This is an Accepted Manuscript of an article published by Taylor \& Francis in Social Work Education on 17 March 2020, available online: http://www.tandfonline.com/10.1080/02615479.2020.1737001. 


\title{
How do statutory social workers respond to feedback on their practice? A small- scale study undertaken in children's services in three English local authorities.
}

\begin{abstract}
:
The underlying processes through which feedback affects practice performance in social work is under-researched. This article reports the findings of a small exploratory scale study focusing on statutory social workers 'experiences of receiving feedback. The study aimed to identify some of the dynamics influencing social workers' reception and use of professional feedback. Findings draw attention to the relational nature of feedback as a key element that influences the uptake of developmental feedback. Other factors identified include the quality of feedback, whether and how feedback is facilitated as well as the positioning of those receiving and giving feedback. Social worker professionality and their engagement with the feedback process were also found to be critical elements. Suggestions offered for enhancing feedback acceptance include using a positive frame, and providing praise feedback as a basis for confidence building and self-efficacy. This study also advocates upskilling supervisors to facilitate reflection and reflexivity to increase social workers self-awareness and place them at the centre of a process in which they have an interactive role to play, increasing their motivation to grow and pro-actively seek feedback, thus validating an organisational learning and development culture where the supervisory relationship drives transformative learning and performance improvement.
\end{abstract}


Keywords:

Feedback processes-reflection- formative- relationship- open mindness- participationreframing

\section{Introduction and context:}

"Feedback is the most powerful single factor that enhances achievement and increases the probability that learning will happen" (Hattie \& Jaeger, 1998, p. 81).

This article is informed by a small-scale exploratory study which aimed to understand responses to feedback from the perspective of statutory social workers working in children's services. Enabling children's social workers in England to improve their performance and thereby promote public confidence in the profession has been a policy concern following the aftermath of child abuse enquiries and published reviews (Laming, 2009; Munro, 2011; Lock, 2013). Munro, in her Final Review of Child Protection in the UK (2011), found the quality of service provided by children and family social workers to be uneven and inconsistent. She recommended a shift from compliance with regulations and policies to a learning culture, with an emphasis on helping social workers develop professional expertise. She urged a move away from a practice model that relies heavily on management targets and a task-focused approach to one that favours analytical thinking, giving attention to how people experience social care processes and relationships.

Concerns about the quality of social work service have been reinforced by continuous inspections of children's services by the Office for Standards in Education, Children's 
Services and Skills (Ofsted). In the period between 2016-17, over two thirds of local authority children's services inspected were rated as 'Inadequate' or 'Requires Improvement' (DFE, 2016) (p 66).

A series of policy and practice initiatives designed to raise the quality of children's social work and ensure that "every child receives expert support and protection" (outlined in DFE (2016) Putting Children First), were introduced including the conception of a voluntary National Assessment and Accreditation System for child and family social workers (NAAS). The programme, which was initiated in the summer of 2018, is due to be rolled out nationally in 2020. The assessment comprises three parts: employer's endorsement, an on-line knowledge assessment, and a simulated practice assessment. In launching this approach (2017) the Chief Social Worker highlighted the need to explore how feedback would be given to social workers following the accreditation test, and the impact of assessment and feedback on "commitment, morale, and career plans" (p.20).

At local authority level, innovation funding (DFE, 2014) has led to initiatives to redesign frontline social care with the aim of promoting creative responses to improve outcomes for children and families. In 2014, the local authorities in which the study was carried out decided to adopt a model of systemic practice with the aim of creating sustained change and enhancing children life chances through relationship-based interventions. Systemic practice supports the idea of a constant feedback loop with individuals in our lives, each feedback input affecting the other. Feedback should be used extensively in social work to assist practitioners examine their skills and knowledge and identify improvements needed (Skills for Care \& CWDC, 2007). 
Measures taken to drive up the standards include the introduction of an assessed and supported first year in employment (ASYE) (DFE, 2015) and the development of three levels of professional accreditation post qualification (child and family practitioners, practice supervisors and practice leaders) (DFE, 2016). These steps institutionalise processes by which social workers may obtain systematic feedback on their practice, within a supervision and assessment system which is intended to embed reflective practice, critical thinking, and sound decision making. They are designed to enhance social workers' knowledge and skills, providing baseline expectations for what postqualified practitioners in children services should know and be able to do. However, there is little empirical evidence available regarding how social workers themselves experience and respond to feedback (other than from service users) and whether they feel able to use the feedback in a way to develop their practice.

In the wider context, mechanisms for performance improvement including the role of feedback are attracting interest in professional education and development. Research studies examining feedback processes and impact (e.g Eva et al, 2012; Sergeant et al, 2009; Mcllwrick, Nair \& Montgomery, 2006; Van Hell et al, 2009; Devloo, Anseel \& De Beuckelaer, 2011) have predominantly been carried out in the business, education and medical fields. No similar research has been identified as specifically applying to social work. There is a lack of consensus on the causal mechanisms through which feedback influences behaviour and performance (Kruger and DeNisi, 1996; Veloski et $a l, 2006$.$) . The emphasis appears to be on the processes surrounding the "giving" of$ feedback, providing rules on how to deliver effective feedback, rather than on the experiences and views of recipients of feedback (Algiraigri, 2014). 
The provision of feedback to professionals in working environments has been addressed by several authors who tend to define or offer prescriptive advice on the processes by which feedback may be best delivered rather than considering the impact feedback has on those individuals receiving it. Hattie and Temperley (2007, p.81) define feedback as "information provided by an agent (e.g. teacher, peer, self, experience, etc.) regarding aspects of one's performance and understanding. It aims to provide "practitioners with information they can use for learning, practice improvement and positive changes" (Gielen et al, 2010; Van del Vleuten and Schuwirth, 2005 cited in Sargeant et al, 2009, p.400). Feedback is conceptualised here as unidimensional and imparted to the other.

Furthermore, feedback on behaviour that has been 'observed' is viewed as more informative than feedback on behaviour 'non-observed' (Smith and Irby, 1997; Ende, 1983; Davis \& Davis, 2001). One hypothesis is that learners can more easily ask for additional information and verify whether they have accurately understood the feedback as well as its meaning (Eva et al, 2012).

The quality of the feedback is also signaled as essential in supporting professionals make the connections between their own work and the scope for future enhancement (Black \& William, 1998) and go through the stages of the assessment cycle: assessment, feedback, reflection and forward action (Quinton \& Smallbone, 2010; Sergeant, 2006). There appears to be considerable agreement that feedback should be clear, timely, mutually understood, specific and relevant with an explanation and an action plan. (e.g Boehler et al, 2006; Hattie and Timperley, 2007; Sergeant et al, 2009) as well as planned, owned by the supervisor, and attending to strengths as well as areas for development (Wonnacott, 2012). 
On-going concern that the influence of the feedback process remains sub-optimal has more recently led to a shift in focus in the wider literature from what individuals delivering feedback must do, to the recognition of the role that recipients of feedback should perform in using feedback for learning and professional development. Sergeant et al (2009) highlight the important role that recipient reflection plays as an essential condition through which feedback is understood, having a fundamental impact on the decision to accept and use of the feedback, reasoning that feedback issued outside a facilitated reflective space has limited influence on performance. Algiraigri (2014) further points out that part of the problem with feedback may be the hierarchical structure of professional environments that foster a one-way flow of information. $\mathrm{He}$ recommends improving workers' ability to self-assess their own performance as the first step of the process. This seems to suggest a role for providers of feedback to promote individuals' self-awareness, in other words, to help them identify professional successes and errors, skills and knowledge and developmental goals.

In social work, there is a broad consensus on what supervision is about and its key functions: educational, supportive and administrative (Kadashin, 1992). While supervision needs to incorporate managerial and administrative tasks essential to protect the agency and the client from poor quality practice it also critical that it attends to the emotional and educational needs of practitioners (Clare, 1988). The educational function relates to the enhancement of knowledge, skills and attitude towards the practitioner's role. The aim is to examine and reflect on the work undertaken, and consider new perspectives, insights and new ways of working. This draws attention to the worker-supervisor relationship, personal values and potential bias (Humphreys, 2007) that each bring to the feedback session. Burnham (2005) argues that selfhood, personal history and life experience will shape the way one supervises and one receives 
supervision. Having open discussions about contrasting perspectives and creating a shared meaning through participation is regarded as crucial to understanding new information that relates to performance and accordingly adjusting practice (McLean, 2006). Thus, the supervisor becomes the facilitator of the reflective process; one who helps coordinate meaning. Wilson (2007, p.18) exemplifies this from a practitioner perspective noting "I hope I can offer a context where we can explore and use 'speculations and meanings' without the constraints of finding the truth". Burnham (2005, p.4) proposes 'relational reflexivity' as “the intention, desire, processes and practices through which [each party] explicitly engages one another in coordinating their resources,..initiating... responding to...and developing, opportunities to consider, explore, experiment with and elaborate the ways in which they relate". Accordingly, the social work supervisory relationship is defined by its collaborative nature, with both supervisor and supervisee influencing the context and content of supervision, through a dialogical process, giving each other feedback on their reciprocal intervention. Supervisors will position themselves in the "not knowing" stance, showing a profound curiosity about the supervisee's narrative in order to co-construct new meanings (Blundo \& Simon (2016, p.43-49)).

The quality of the relationship and context for supervisee may therefore be key factors influencing the use of feedback. The mindset of the feedback recipient also appears to have an effect on feedback utilisation. Brett \& Atwater (2001) believe that "individuals who are open minded or who have a strong learning orientation are more likely to perceive feedback as having value regardless of the results received" (cited in Taylor and Bright, 2011, p. 435). In contrast, individuals who tend to be guarded are more likely to resist feedback that is invalidating (Dunning, 2005) 
Existing studies highlight important conditions for enabling individuals to engage with and appraise the feedback received before initiating change. The quality of the feedback; participation; the psychological state of the recipients; facilitation of learning through reflection; the quality of the relationship, and context for feedback (e.g. formative, observed) all appear to influence the uptake of feedback to improve knowledge, skills and performance. This suggests that feedback delivery (how, when and by whom) is not the only element that matters. How feedback is experienced, fears and motivators for seeking feedback; the emotional impact of negative feedback and the use of strategies to make feedback more palatable may also be critical. Nonetheless, there are limited studies on the recipients of feedback themselves.

In developing the research strategy, the stance taken was to adopt a methodology which would enable in-depth exploration of the processes which may help social workers hear, make sense of, accept and use feedback to enhance their work performance.

\section{Methodology}

Research approach

This small-scale exploratory study, informed by a social constructivist paradigm, seeks to explore the provision of feedback within a statutory children services' setting.

\section{Ethics}

Ethical approval was sought and received from the Faculty Research Ethics Committee of Kingston University and St George's University of London. Research questions include how, when and by whom it is provided and, how do recipients of feedback view 
its potential to improve performance. A participant information sheet and written consent to participate were emailed to all social workers with an invitation to take part in the study.

\section{Methods}

Quantitative and qualitative methods were used to answer research questions to study social workers' reactions to feedback in-depth. An anonymous online questionnaire was made available to all social workers in front line roles in the three English authorities through a survey monkey web link, sent via email. The survey primarily included closed questions with a small number of open-ended questions to invite participants to share their experiences and views. The survey was also used to enlist people who might be interested to participate in a face-to-face interview. The first six social workers, who expressed an interest to take part and provided written consent, were interviewed. The interviews were semi-structured and open-ended questions were used to explore participants' perceptions.

Table 1- participants interviewed

\begin{tabular}{lll}
\hline Participants & Gender & Number of years post qualified \\
\hline Zia & Female & 11 \\
Adele & Female & 10 \\
Kelly & Female & 3 \\
John & Male & $>1$ (newly qualified) \\
Gio & Male & 4 \\
Selma & Female & 4.5 \\
\hline
\end{tabular}

Analysis:

Two forms of analysis were undertaken. Descriptive statistics were generated from the survey responses. Additionally, a qualitative analysis of responses to the open-ended 
questions was undertaken. This analysis raised further questions, which were used to inform the main research method comprising in-depth semi-structured interviews to explore thoroughly how social workers themselves perceived the feedback they were given, in line with grounded theory methodology and inductive analysis (Sbaraini et al, 2011).

The interviews, with written participants' consent, were audio taped and transcribed verbatim. This raw data was then analysed using qualitative analysis techniques, informed by the inductive and investigative-grounded theory approach (coding common themes and patterns as a basis for analysis) (Boyatzis, 1998). In line with thematic analysis, coding was achieved in phases to create meaningful patterns. Initially, recurrence of words that appeared in the six transcripts were coded and regrouped in small units (themes). After multiple readings of the data themes were merged into categories and theoretical formulations started to emerge from the data. The transcripts were then reduced to what was relevant to the themes and categories that had been identified, while an open mind was kept for potential new themes or categories to be identified in order to obtain theoretical saturation (Glaser \& Strauss, 1967). Direct quotations were selected to illustrate the findings. The categories were then organized and defined in headings, and subheadings, primarily following the order of the research questions.

\section{Response rate}

34 social workers responded to the survey (10.6\% of eligible respondents, 34 out of 320 individuals with the title of "social worker" employed in front line services). The survey remained open for three weeks and one reminder was emailed to all social workers two weeks after the initial invitation to participate was sent out. There were 
little steps taken to boost the profile of the research study and response rate (a presurvey launch organized or weekly responses update circulated to staff might have contributed to an increase in the number of responses). Given that these are frontline busy social workers, the low response rate was predictable. However, it also showed that for those who responded this was live and relevant issue.

Six social workers who were willing to take part in an interview were selected, representing a range of professional experience. These included two social workers over 10 years post-qualification experience, three qualified between three to five years, and one newly qualified.

\section{Survey findings and analysis}

The majority of 34 respondents $(n=34)$ to the online anonymous survey $88 \%(n=29)$ indicated that they received both formal and informal feedback primarily from their team manager $94 \%(n=30)$, service users $84 \%(n=27)$, and peers $78 \%(n=25)$. The majority $93 \%(n=28)$ rated their team manager's feedback as "useful" or "very useful". Almost all feedback was provided during supervision 93\% $(\mathrm{n}=28)$, upon submission of written work $77 \%(n=23)$ and by service users after intervention $67 \%(n=20)$. Feedback provided during supervision predominantly related to work tasks $66 \%(n=18)$ specifically in relation to the completion of allocated work $70 \%(\mathrm{n}=19)$. This suggests an organisational focus on the monitoring function of supervision and supervisors prioritising feedback on task completion. Participants' narratives suggest that feedback helped them $86 \%(\mathrm{n}=23)$ reflect on their effectiveness and assisted them in identifying

when changes were needed. A little more than half of respondents $(n=14)$ indicated that they genuinely looked forward to getting feedback on their practice with almost three- 
quarters of respondents $(\mathrm{n}=19)$ indicating that they felt able to step back and reflect on the validity and worth of the feedback received. While feedback provision is desired and valued by workers, they indicated that supervisors often claimed to be too busy to provide feedback on practice, based on observations, resulting in workers assuming that feedback is not vital. This internalised thought may stay with them throughout their career, discouraging them from seeking regular feedback.

The majority $96 \%(n=25)$ felt positive about developmental feedback and saw it as an opportunity to do things differently in future. When receiving positive feedback, workers felt reassured $80 \%(n=21)$, grateful $84 \%(n=22)$, motivated $65 \%(n=17)$ and their confidence was boosted.

Respondents were more divided in relation to the role of feedback in setting and reviewing individual targets and providing praise for the work completed. Under onethird $(n=10)$ did not explicitly agree that they received positive acknowledgement of good practice. This indicates a perception that feedback provided focussed on the standard of tasks undertaken and skills to improve and less so on their successes and strengths and more generally on the professional development of workers and using feedback to support workers' resilience and motivation.

For some, receiving feedback was not a fully positive experience. Over a quarter $(n=7)$ indicated that they felt anxious before receiving feedback. Almost a third $(n=8)$ revealed that they had a tendency to focus on the negative comments made. Six workers felt suspicious about the motives of the person giving feedback and four had felt upset following feedback they had taken as critical of their work. After receiving 
developmental feedback, a fifth $(n=5)$ of the respondents had felt shocked before accepting it.

Common responses to an open question asking for views on how the provision of feedback could be improved were in favour of more regular, structured, evidence-based feedback (through direct observation of practice); and routine provision of formalised and balanced feedback within reflective supervision to alleviate apprehension. Time and space to process the feedback on practice was also highlighted.

\section{Interview findings and analysis}

Several questions emerging from the analysis of the survey were selected for further exploration during the interviews. Key questions were: does praise or lack of praise impact workers' morale and motivation to develop their practice? Are social workers genuinely interested in using direct observations of practice to get more feedback? Is there an emotional response to feedback?

From the qualitative analysis of the in-depth interview four main themes emerged: the nature and context for feedback, "taking the feedback", managing the relationship and "what works".

\section{The nature and context for feedback}

In considering the nature and context for feedback, it was perhaps not surprising that the six participants received feedback formally and informally, both within and outside of supervision as this had been indicated in the survey results. All mentioned the lack of time and space afforded to feedback in busy work environments. Within supervision, 
feedback was perceived as "unintentional", casework related, unidirectional and often hurried.

“There's definitely ... some element of feedback in every supervision (pause) perhaps not in an intentional way necessarily, but because you 'talking about the work you've done, so your manager will talk about things you haven't done... which perhaps not intended as feedback but is feedback" -Gio

The participants acknowledged that feedback in supervision tended to focus more on casework and the tasks to be executed than on individual workers' use of self, relationship dynamics and direct work skills, more on the case decisions and desired outcomes than social work processes.

"We may just have case consultations but that is about casework so not about individual worker's feedback, it's about cases and ...not about how you are working as an individual with this family." - Zia

Feedback on work performance mostly related to written work. Whilst feedback on directly observed practice was reported to be "helpful", participants remarked it was irregular and infrequent, with limited opportunities for joint working with peers hampering the prospect of feedback on observed practice.

"I felt we get more feedback in terms of performance generally in term of the written work, rather than delivered work which seems to be back to front in many ways..." - Gio

Outside of supervision, feedback occurred at times of crisis, when something had gone wrong, or when a complaint had been made. This felt "brash" and "tacked on". Such feedback occurred spontaneously in the form of comments made to workers in relation 
to their work and not as a tool used systematically with reflection in supervision to improve learning.

Participants whose managers were predominantly the providers of feedback commented that they valued feedback from a manager more than feedback from the peer group. "I want to know what I am doing right... I think the manager, somebody who has experience over me are the right people to give that" - John

However, all interviewees considered peer feedback in a positive light and wanted to have more opportunities to share practice experiences with their peers. Some feedback was obtained from service users when social workers pro-actively sought their views following interventions. Such feedback was generally in relation to service provision and was valued.

\section{2. "Taking the feedback"}

All participants talked about their approach to "taking feedback". They found "feedback" relevant to practice, nonetheless they did not actively ask for feedback on their practice, apart from one practitioner who, as part of his ASYE portfolio, was required to obtain feedback from various sources. Common responses were associated with the importance of knowing their individual strengths and weaknesses in order to improve their practice.

"I want to make it better for people ... by being better myself it means that they will get a better service and ... a more positive experience." - Abby 
While they found praise particularly beneficial in order to remain enthusiastic about their work, there was an admission that practice can always be improved and they saw value in developmental feedback to enhance performance.

"We all like to hear what we are doing well, but even negative feedback can be essential for our own practice ...but I know that people find that difficult to give ....and sometimes all you do get is very one-sided feedback" - John

One participant compared the emotional positivity that came from positive feedback to "blue sky moments" and commented:

"Positive feedback is incredibly important to me ... Knowing that my manager is happy with me ... that's a kind of general sort of approval of what I do and sort of saying ' you did a good job"”. - Abby

Positive feedback was congruent with the participants' self -perceptions and selfexpectations. Reducing uncertainties by providing positive feedback on accomplished tasks was identified as helpful and supportive of participants' sense of achievement, self-efficacy and motivation to continue with their approach to practice with the knowledge that their practice is sound and effective.

"We are all human and we all go through bad days and good days and even by saying a "thank you" to a worker or "well done, that was a good report" that lifts, boosts them because the job is so stressful as it is that if you are not getting any feedback how do you know you are doing right or wrong?" - Zia

The more experienced workers reported that they only occasionally received feedback. Not receiving feedback for them meant they were doing a good job. Feedback tended to be informal, often given spontaneously after a work intervention. 
Furthermore, participants considered feedback within their organisation hierarchical structure as something that is given from more to less experienced staff. Participants felt generally suspicious when taken aside to be told they would be given feedback and envisaged criticism from their manager.

"I think people are quite wary of it. They tend to anticipate it as quite negative. People seem to be in one of the two positions. It is either great or awful". - Gio

This appeared to result in participants rarely engaging in proactively seeking feedback from their supervisors. Instead, they reported that they waited to be told about their performance.

Negative feedback often came as a shock and something that they had not recognised they were doing. Participants spoke evocatively of the emotions negative feedback raised, including taking it personally, distress and feeling upset despite feedback relating to professional behaviours and performance. It appeared to have an adverse impact on their motivation to continue to do the work.

"I do tend to take constructive feedback quite personally. I feel deflated a day or two. I can't be bothered now, I 'm not gonna do anything. I 11 just shut up. By day 3, I am back to normal” (...) "I feel less energetic, less available the next 2 days. I put my headphones on and work" - Zia

One participant described the shock, pain and upset she had experienced after she was told about a behaviour she was enacting, something that she had not realised she was doing (i.e. interrupting others). While recognising the difficult emotions the feedback had triggered, she reported that it had been an "incredibly good piece of learning" and she had used this to improve her practice. 
"It was so painful and so upsetting. I remember crying... I accepted it. It did not take me long to realise that was what I was doing." - Abby

Participants made reference to "reframing" as a technique to re-construct the feedback provided in a more positive light and consider its usefulness.

"I've always gone on the stance of twisting it around so rather than taking it really negative and personal if I twist it around and think of it as positive..." - Zia

\section{Managing the relationship}

Participants talked about their approach to "managing the relationship" with their supervisor in relation to receiving feedback. They commented that feedback was often influenced by their manager's supervisory style and interpersonal skills and the type of relationship they had with their supervisor. They referred to the verbal and non-verbal communication styles and how these fostered (or not) open discussions. A more approachable and collaborative type of supervisory relationship promoted open discussions on the work undertaken and the sharing of views and learning. All highlighted the importance of having an open and honest dialogue for feedback to be both given and received. Participants outlined strategies they have used to try and foster a positive relationship with their manager in order to be able to have open discussions.

" One of the things that I've very much had to learn ... was the way that you kind of ask those questions because I got told quite a lot of the time that I was quite defiant in terms of my recommendations so it's very much about changing the way that you approach your manager but also being conscious of how your manager can be approached..”. - Kelly

\section{4. "What works?"}


Each participant was asked to identify aspects of feedback that "worked". For one participant, peer feedback and co-working had created an opportunity for him to receive feedback based on observed practice. He described how the specific comments made by colleagues had "stayed" with him and help build on his skills and knowledge.

"So if you are co-working or if you have the observation then you have that direct and specific kind of feedback around what you're doing...it's not about your perception of a case, or your assessment of a case or what you remember from that visit, it's someone actually seeing it and able to give their views or break it down or do the same sort of soundboard exercise having been there...it s a lot more useful" - Gio

Another social worker highlighted factors that motivated her to engage with the feedback and take her performance to the next level. This was provided by an external source, following an observation and was "evidence based" and "trustworthy", specific and clear, with practical suggestions on how to improve and summarized in writing. "She'd taken time to properly observe my practice... I felt she had a good understanding... She gave me examples... she used research to back that up as well so it was evidence based. Then she'd written the feedback and ... given further examples." - Kelly

This was echoed by another participant (Abby) who pointed out that receiving feedback from an external source (a coach) had enabled her to open up on practices she wanted to develop. She highlighted the value of collaboration in a feedback session, including being invited to discuss areas of her practice she wanted to develop and her ideas, noting the positive impact of being helped to define and formulate her ideas before exploring possibilities for action. This had had a positive influence on her wanting to follow through an action plan. 
"It is feedback... that I've developed in the conversation saying "I really would like to try and do that a bit differently" and then he writes out .... little action point, ... from my own words but it is effective... I think people approach change from a position of thinking about their strengths and things they've done well, things that they've overcome, their sense of agency and actually building on that and calling on that to overcome current difficulties..." - Abby

Two participants (Zia \& Selma) highlighted the relevance of the context for feedback and how having an informal dialogue made it possible for worker and supervisor to explore each other's perspectives on work performance and reach a mutual understanding of what actions needed to happen and agree on possible ways forward. One participant (Zia) also spoke about how she sometimes reframed negative feedback messages in positively framed messages, in order to remain motivated at work. "It's fine giving me feedback but then if you're gonna give me constructive feedback on stuff that actually I may not agree with you on, you think "actually, let's just have a discussion" - Zia

Participants (Zia \& John) noted that feedback needed to contain positive elements, suggesting that a positively framed feedback conversation was desirable to engage workers on their performance, starting with specific skills they had exhibited, moving on to constructive comments to help them adjust or fine tune their skills. One individual suggested that moving from general comments to more specific details was helpful.

"I think positive constructive feedback is better than just telling somebody "you've done this wrong." I think the way it's brought to you is very important"- John

\section{Discussion:}


The data obtained in this small scale study of the experiences and perceptions of a small group of social workers of feedback and the elements that play a role in their motivation to use feedback to enhance their practice are in many respects similar to what others have detected (Sergeant et al, 2009; Hattie and Temperley, 2007; Eva et al. 2012; Van Hell et al, 2009).

A key factor appears to be related to the practice context for feedback. Feedback is often provided at times of crisis or in between interventions, rushed and in the form of comments (often unfavorable) made in relation to the work and not as a tool systematically used with reflection, in supervision, to improve practice skills (Sergeant et al, 2009). Performance feedback appears not to be provided formally in supervision, except for those who are newly qualified. It may be that feedback given outside a facilitated reflective space has limited influence on performance as reflection is what makes possible transformative learning (Sergeant et al 2009, Moon, 1999). It may therefore be helpful for performance feedback to be integrated into supervision discussions, to normalize its practice and alleviate feelings of anxiety. Although participants reported valuing both positive and constructive feedback and expressed a desire for more regular and more formalized feedback, a contradiction was found in that they openly affirmed rarely seeking feedback but rather waiting to be told about the standards of their work. Subsequently, this raises a question in term of workers' professionalism and the responsibility assigned to them upon professional registration to use supervision to support and enhance the quality of their social work practice (HCPC, 2012). Evans (2002, pp.6-7) refers to "professionality", defined as "an ideologically, attitudinally, intellectually, and epistemologically-based stance on the part of an individual, in relation to the practice of the profession to which s/he belongs, and which 
influences her/his professional practice”. Workers' lack of initiative in seeking feedback may be due to the fear of negative feedback based on their experience that feedback is most often provided when there are difficulties. It may be, therefore, that not initiating feedback diminishes their engagement with learning and development, and consequently professional growth.

Participants commented that feedback predominantly related to their accounts of interventions, verbal or written, and not often on practice that had been directly observed. Yet, all social workers interviewed spoke about how helpful and informative feedback was following an observation of practice. Manning (2008) referring to Goffman's (1974) frame analysis defines performance as a "seeable : something that one sees, behavior, not a value, a belief or an attitude (...) a sequence of gestures, postures, verbalizations or actions seen by others (seen, and not talked about) and responded to" (p.680). Consequently, one wonders how feasible it is to provide accurate feedback that addresses specific elements of one's practice without seeing the effects of the person in action. It may be therefore that feedback needs to be related to practice that has been observed in order to be regarded as credible, helpful and grounded in practice evidence.

Specific positive feedback appears to encourage workers to repeat desired behaviors. Participants with three years or more in practice revealed that they did not often receive praise feedback, while recognizing how important positive feedback was for them in term of motivation and validation that they were doing a good job. This raises concerns in relation to the process that would normally support workers to maintain or continue to develop their sense of confidence and self-efficacy. It also disregards the Broaden- 
and-Build Theory of Positive Emotions (Fredrickson, 2001) which hypothesizes that positive emotions increases people's momentary thought-action repertoires, which in turn has an effect on people's personal resources, intellectual and artistic behavior, urge to explore and push the limits, physical well-being and psychological resilience. Bandura (1977) remarked that giving people a clear objective and a means to appraise their progress towards that objective significantly increases the probability that they will achieve it. He also observes that the more individuals believe in their ability to be able to carry out a task, the more likely they are to carry it out successfully and obtain a reinforced sense of self-efficacy. The assumption that experienced workers know how to carry out their work autonomously and that feedback on what they accomplish routinely is not necessary, misjudges the role of the feedback loop (Batson, 1972) and the principles of circularity (Cecchin, 1987) as positive tools for creating potential for behavioral change. It may be, therefore, that providing individuals with information about their actions in a timely reflective manner will promote change and encourage more desirable behaviors and skills mastery.

Another key issue seems to be that feedback is never delivered or received in a vacuum (Hattie \& Timperley 2007). The various identities (e.g. gender, race, class, culture, sexual orientation, social location, professional status) that shape how worker and supervisor see the world, will influence their positioning during feedback conversations and the decision to use feedback. If knowledge is socially and culturally specific and constructed over time (Harding, 1991), feedback assessment, provision and interpretation will be connected to the standpoint held by the individuals involved (Cowburn, Nelson \& Williams, 2000). It may, therefore, be helpful to engage the recipients of feedback on how they understand this and show curiosity as to where this 
fits within their own self-appraisal through an interactive process, a dialogue, in order to try to coordinate meaning. Pearce \& Pearce (2000) suggest a process of "Coordinated Management of Meaning" (i.e. how do we create meaning together). The check-in process that participants referred to, encapsulate this principle of creating shared meaning.

The emotional impact of receiving negative feedback experienced at personal level even though feedback related to professional behaviors is significant. There was a sense that performance feedback conversations were uneasy for supervisors whose fears perhaps about hurting workers' feelings and damaging the working consensus, may lead to feedback messages being delivered in a way that comes across as brash, authoritarian and not specific enough to be utilized. The way oral feedback is framed influences people's emotional response - acceptance or defensiveness. Framing refers to the "packaging of the message independent of the message content" (Van de Ridder et al, 2015). It may be, therefore, that the ethical position of the feedback provider (position of beneficence, supportive and empowering) and strategy for feedback intervention (for instance through facilitating a conversation, use of circular questions) will also influence acceptance and assimilation of feedback. It is interesting to note that some participants have developed strategies to handle negative or brash feedback and be able to do something with it (for example, reframing the message delivered in more positive terms by changing the frame of reference). Accordingly, it may be helpful to empower workers with skills about how to receive feedback and deal with it in order to increase feedback use in furtherance of professional development.

\section{Limitations}


There are several limitations to this study that deserve attention. On one hand, the low response rate of eligible respondents invited to complete the questionnaire as well as the selection of a convenience sample for the face-to-face interviews reduce confidence in the generalizability of the data obtained. On the other hand, the findings obtained from the in-depth exploration of social workers' experiences of feedback deepen our understanding of the causal mechanisms through which feedback influences behavior and performance. The intention of the study was to learn from participants themselves how they experience feedback, the meaning they put on it and how they interpret what they experience. Put simply to give a voice to the experiences of participants. A greater limitation of the research is related to the researcher being prone to bias and subjectivity in their analysis of participants' responses partially due to the nature of this study (an exploratory study) as well as not having many years of experience in the field of research. The researcher mitigated this dilemma by working alongside an experienced academic scholar who provided mentoring, giving constructive feedback and acting as a sounding board to explore ideas and themes arising from the research being carried out. This step intended to establish the reliability of the interpretation process and representation of the participants' stories and confidence "trustworthiness" (Lincoln \& Guba). As for the conclusions, they support a number of theories born out of research undertaken in the business, education and medical fields, thus corroborating their significance in furthering our understanding of what helps social workers to accept and use feedback for development. As a final point, the study was carried out in 2016, and since, there has been a growing interest in up-skilling newly appointed practice supervisors with a particular focus on developing critical reflection facilitation and coaching skills to promote professional development (Firstline and practice supervisor development programmes). 


\section{Conclusion:}

This study has found that certain indicators appear to play a role in social workers' acceptance and uptake of feedback to improve their practice. How, when and by whom feedback is delivered, the quality of the feedback (clear/ specific/ relevant), and how it is framed (positively/ negatively); the active participation of recipients in selfevaluation and seeking of feedback; the psychological state of the recipients; the context for feedback (observed/ provided within supervision) all have an influence on whether the feedback will be used for development. Above all, the findings point to the relational nature of feedback as the key element of the feedback process. The quality of the relationship between recipient and provider of feedback (and fear of damaging the relationship), appear to facilitate or constrain the exploration of practice performance. A supervisory relationship defined by its collaborative essence where the expert-novice positions no longer matter so much but the lived experience of the other is what is seen as important and as driving the motivation to explore how to do things differently to benefit those at the receiving end of the service. It may be, therefore, that having a positive regard for the other and showing a profound curiosity in relation to the stories connected to practice behaviors as well as recognizing what is going on for the supervisor internally and within the interactions, will help foster a dialogue based on the taking and giving of constructive feedback, each influencing the way the conversation evolves and is co-constructed, as well as understood.

Although it is recognized that there are clear limitations to this study because of its scale, there are important indicators for practice development. The skillful facilitation 
of reflection may be of equal importance to the provision of high quality feedback for feedback to influence professional growth. Supporting supervisors to develop their skills as facilitators of critical thinking, as well as their understanding of what constitutes effective feedback may be needed. The findings indicate that social workers do not seem to be well prepared to deal with constructive feedback. Creating regular opportunities for observation feedback might help normalize the provision of feedback, reduce people's apprehension and make familiar processes for practice enhancement: co-working and peer feedback, live supervision and role play can all be used for strengthening practice. The importance of the supervision relationship as a nexus for performance improvement and development cannot be underestimated. Perhaps though, the most critical element is promoting social worker professionalism in seeking feedback, analyzing feedback for its validity and worth, managing emotions in relation to evaluative feedback perceived as critical and using directive feedback to develop robust professional development plans. 


\section{References}

1. Algiraigri,A. (2014) Ten tips for receiving feedback effectively in clinical practice. Medical Education Online, [S.1.], ISSN 1087-2981. Retrieved from http://med-ed-online.net/index.php/meo/article/view/25141

2. Bandura, A. (1977). Social Learning Theory. Oxford, England: Prentice-Hall.

3. BASW (2012) The Standards for employers of Social Workers in England. Retrieved from: https://www.basw.co.uk/system/files/resources/basw_1254610_0.pdf

4. Bateson, G. (1972). Steps to an Ecology of Mind: Collected Essays in Anthropology, Psychiatry, Evolution, and Epistemology. University of Chicago Press.

5. Black, P. and Wiliam, D. (1998). Assessment and classroom learning. Assessment in Education: Principles, Policy and Practice, 5(1): 7-73.

6. Blundo, R. and Simon, J. (2016). Solution-Focused Case Management. Springer publishing company- p43-49

7. Boehler, M.L. et al. (2006). An investigation of medical student reactions to feedback: a randomised controlled trial. Medical Education, Volume 40, No 8, 746-749

8. Boyatzis, R. (1998). Transforming Qualitative Information: Thematic Analysis and Code Development. Sage

9. Brett, J. and Atwater, L. (2001). $360^{\circ}$ feedback: Accuracy, reactions, and perceptions of usefulness. Journal of Applied Psychology, Vol 86(5), 930-942. 
10. Burnham, J. (2005). Relational reflexivity: a tool for socially constructing therapeutic relationships. In C. Flaskas, B. Mason and A. Perlesz (eds), The Space Between: Experience, Context, and Process in the Therapeutic Relationships. London: Karnac.

11. Cecchin, G. (1987). Hypothesizing, Circularity, and Neutrality Revisited: An invitation to Curiosity. Family Process, 26 (4), 405-413.

12. Clare, M.(1988). Supervision, Role Strain and Social Services Departments. British Journal of Social Work, volume 18, Number 5Pp. 489-507.

13. Cowburn, M., Nelson, P. \& Williams, J. (2000). “Assessment of social work students: standpoint and strong objectivity”. Social work education, Vol.19, NO.6.

14. Davis, J.R., Davis, A.B. (2001). Effective training strategies: A comprehensive guide to maximising learning in organizations. San Francisco. Berret Koehler Publishers.

15. DeNisi, A.S., \& Kluger, A.N. (2000). Feedback effectiveness: Can 360- degree appraisals be improved? Academy of Management Executive, 14, 129-139.

16. Department for Education. (2014). Overview report Department for Education Children's Social Care Innovation Programme. Ref: DFE-00379-2014 PDF, $540 \mathrm{~KB}, 13$ pages

17. Department for Education (2015). Assessed and supported year in employment. Policy paper. Retrieved from:

https://www.gov.uk/government/publications/assessed-and-supported-year-inemployment-asye/assessed-and-supported-year-in-employment 
18. Department for Education (2015). Knowledge and skills: practice leaders and practice supervisors government consultation response. Ref: DFE-00291-2015 PDF $157 \mathrm{~KB}, 8$ pages.

19. Department for Education. (2016). Putting children first: delivering our vision for excellent children social care. Ref: DFE-00158-2016 PDF, 5.88MB, 72 pages

20. Department for Education. (2017). Confidence in practice: child and family social work assessment and accreditation system. Government consultation response.

21. Department of Health. (2016) Making the difference together: Guidance on gathering and using feedback about the experience of social work from people who use services and their carers. Retrieved at assets.publishing.service.gov.uk/government/uploads/system/uploads/attachmen t_data/file/495517/Making_the_difference_together_social_work_adult_mental _health_A.pdf

22. Devloo, T., Anseel, F. \& De Beuckelaer, A.(2011). Do Managers Use Feedback Seeking as a Strategy to Regulate Demands-Abilities Misfit? The Moderating Role of Implicit Person Theory. Journal of Business Psychology (2011) 26: 453465

23. Dunning, D. (2005). Self-Insight: Roadblocks and detours on the path toward knowing thyself. New York, NY: Psychology Press.

24. Ende, J. (1983). Feedback in clinical medical education. JAMA 150:777-781

25. Eva, K., et al. (2012) . Factors influencing responsiveness to feedback: on the interplay between fear, confidence, and reasoning processes. dv Health Sci Educ Theory Pract. 2012 Mar; 17(1): 15-26. 
26. Evans, L. (2002b). Reflective Practice in Educational Research: Developing Advanced Skills (London, Continuum).

27. Fredrickson, B.L. (2001). The Role of Positive Emotions in Positive Psychology

28. The Broaden-and-Build Theory of Positive Emotions. Published in final edited form as: Am Psychol.; 56(3): 218-226.

29. Gielen, S. (2010). Improving the effectiveness of peer feedback for learning. Learning and Instruction 20:304-315

30. Glaser, B. and Strauss, A. (1967). The Discovery of Grounded Theory: Strategies for Qualitative Research. London: Wiedenfeld and Nicholson 81 (86).

31. Goffman, E. (1974). Frame analysis. New York. Basic Books.

32. Harding, S. (1991). Whose Science? Whose Knowledge? Ithaca, N.Y.: Cornell UP.

33. Hattie, J. and Timperley, H. (2007). The Power of Feedback. Review of Educational Research 77: 81

34. Hattie, J. \& Jaeger, R. (1998). Assessment and classroom learning: A deductive approach. Assessment in Education: principles, policy \& practice 5(1), 111-122.

35. HCPC Health and Care Professions Council (2012). Standards of proficiency. Retrieved at: http://www.hcpcuk.org/assets/documents/10003B08StandardsofproficiencySocialworkersinEngland.pdf

36. Humphreys, C. (2007). A health inequalities perspective on violence against women. Health and Social Care in the Community 15(2), 120-127

37. Kadushin, A. (1992) Supervision in social work. Third Edition. Columbia University Press. New York. 
38. Kluger, A. \& DeNisi, A. (1996). The effects of feedback interventions on performance: A historical review, a meta-analysis, and a preliminary feedback intervention theory. Psychological Bulletin, 119, 254-284.

39. Lincoln, Y. \& Guba, E. Naturalistic enquiry. Thousands Oaks (CA): Sage Publications; 1985.

40. Manning, P. (1998). Goffman on Organizations. Organization studies, 29(5):677-699.

41. McLean, G. \& DeMars, S. (2006), Organization development: Principles, process, performance Perf. Improv., 45: 41-43.

42. McIlwrick, J., Nair, B. and Montgomery, G. (2006). 'How am I doing?': many problems but few solutions related to feedback delivery in undergraduate psychiatry education. Academic Psychiatry, 30(2), 130-135.

43. Moon, J. (1999). Reflection in learning and professional development, theory and practice, London: Kogan Page.

44. Munro, E. (2011). Review of child protection: final report - a child-centred system. Ref: ISBN 9780101806220, Cm 8062 PDF, 1.73MB, 178 pages.

45. Ofsted (2017). The Annual Report of Her Majesty's Chief Inspector of Education, Children's Services and Skills 2016/17. Retrieved from: https://assets.publishing.service.gov.uk/government/uploads/system/uploads/atta chment_data/file/666871/Ofsted_Annual_Report_2016-17_Accessible.pdf 46. Pearce, W. and Pearce, K. (2000) . "Extending the Theory of the Coordinated Management of Meaning ("CMM") Through a Community Dialogue Process". Communication Theory, Vol. 10. 
47. Quinton, S. \& Smallbone, T. (2010). Feeding forward: using feedback to promote student reflection and learning - a teaching model. Innovations in Education and Teaching International, 47:1, 125-135.

48. Sergeant, J. (2006). Multi-source feedback for physician learning and change. Halifax, Canada: Halcraft Printers Inc. (Doctoral dissertation, Maastricht University, NL)

49. Sergeant, J.et al. (2009). Reflection: a link between receiving and using assessment feedback. Adv in Health Sci Educ.14:399-410

50. Skills for Care and CWDC (2007) Providing Effective Supervision retrieved from: https://www.skillsforcare.org.uk/Document-library/Findingand-keeping-workers/Supervision/Providing-Effective-Supervision.pdf

51. Smith, CS., Irby DM, (1997). The roles of experience and reflection in ambulatory care education. Acad Med 72:32-35

52. Taylor, S. and Bright, D. (2011). Open-mindedness and defensiveness in multisource feedback processes: A conceptual framework. The journal of Applied Behavioural Science. SAGE Publications

53. The Lord Laming report. (2009). The protection of children in England: A progress Report. London: The Stationary Office. Retrieved at: http://dera.ioe.ac.uk/8646/1/12_03_09_children.pdf

54. Van de Ridder, J. (2015). Framing of feedback impacts student's satisfaction, self-efficacy and performance. Adv Health Sci Educ Theory Pract. 20(3):803-16.

55. Van Hell, E. et al. (2009). Instructiveness of feedback during clerkships: influence of supervisor, observation and student initiative. Medical teacher, 31(1), 45-50. 
56. Veloski, J. et al (2006). Systematic review of the literature on assessment, feedback and physicians' clinical performance: BEME Guide No. 7. Med Teach 28: $117-28$.

57. Wilson, B. (2007), Nurses' knowledge of pain. Journal of Clinical Nursing, 16: $1012-1020$.

58. Wonnacott, J. (2012). Mastering Social Work Supervision. Jessica Kingsley Publishers. 